\title{
The National Clinical Skills Competition Promotes the Construction of a Comprehensive Training Program for Chinese Medical Students
}

\author{
Jing Yang ${ }^{1}$, Si-min Huang ${ }^{1, *}$, Chun-ting Lu $^{2, *} \&$ Lie Feng ${ }^{1}$ \\ ${ }^{1}$ Department of Internal Medicine, The First Affiliated Hospital, Jinan University, Guangzhou, China \\ ${ }^{2}$ The Science \& Education Office, The First Affiliated Hospital, Jinan University, Guangzhou, China \\ *Correspondence: Si-min Huang, Department of Internal Medicine, The First Affiliated Hospital, Jinan University, \\ Guangzhou, 510630, China. E-mail: doctxp@126.com and Chun-ting Lu, The Science \& Education Office, The First \\ Affiliated Hospital, Jinan University, Guangzhou, 510630, China. E-mail: jnuchuntinglu@163.com
}

Received: January 21, 2018

Accepted: February 11, 2018 Online Published: March 2, 2018

doi:10.5430/jct.v7n1p81

URL: https://doi.org/10.5430/jct.v7n1p81

\begin{abstract}
To explore an efficient training program based on an analysis in organizing seven sessions for the National Clinical Skills Competition in China. Each year, 6-12 excellent medical students of our university are selected as an observation team. Comparisons of the teaching characteristics were performed in this study. An optimal curriculum implementation, specific clinical teaching scenarios and evaluation methods were gradually obtained and improved. Teaching effects were satisfactory. Among seven sessions, the eighth session was the best. Curriculum construction and training team building are formed synchronously through this National Clinical Skills Competition. Clinical skills training should be designed and evaluated effectively in order to increase the comprehensive capacities of medical students.
\end{abstract}

Keywords: clinical skills, training, scenarios, national competition

\section{Introduction}

The National Clinical Skills Competition for college students has been formally organized by the Ministry of Education of China each year since 2010. The aim of this competition is to promote the further development and innovation of the clinical teaching system in order to raise the practice and teamwork abilities of medical students. The competition items cover approximately 100-130 relevant skills and items of knowledge in diagnostics, internal medicine, obstetrics and gynecology, pediatrics, emergency medicine, intensive care medicine, nursing, otolaryngology, ophthalmology, dermatology, infection, medical imaging, pathological science, and the medical humanities. Furthermore, these basic items can be subdivided into detailed techniques and several hundred clinical operations according to different specialties in clinical practice and teaching. In this case, it is necessary to design and establish one scientific and optimal education system that is capable of meeting this challenge. To date, Jinan University has participated in the national competition seven times since 2011, and good results and satisfactory teaching effects have been achieved in 5 of the 7 times when the university has entered the final match. It is a large teaching and training system that requires good cooperation and teamwork among medical faculty members and students. The National Clinical Skills Competition covers more than $90 \%$ of Chinese medical colleges and universities. Its aims are to establish the centrality of clinical skills training in medical education, to start demonstration projects, to establish the scientific standardization of clinical practical curricula and teaching criteria for simulation education, to promote the cultivation of outstanding medical talent, to ensure the continual development of quality clinical education, and to launch a reasonable training system (Wang 2012). Clinical skills competitions have been changing from simple simulation-oriented techniques to medical or virtual simulations on a high-fidelity medical simulation platform that are closely merged with real clinical cases in order to encourage medical students to develop comprehensive capacities including clinical theory; clinical thinking; clinical decision-making abilities; skillful, accurate, and standardized operations; rapid adaption to changing circumstances; and teamwork. This change shows that a clinical skills competition acts as one widely recognized means of teaching evaluations. According to the national authority organization of the competition, the whole process consists of two parts. First, preliminary matches are held in six administrative areas in the northeast, north, east, central, south and 
west of China. Second, approximately $36 \%$ of the top colleges enter the national finals (Jiang 2016).

Our study focuses on the design and establishment of a clinical skills training system for preparing for and attending the South China divisional qualifying match each year because our university team has qualified for the final match 5 times. Therefore, the competition processes, training courses, teaching effects, competition results, teaching experience and lessons are summarized and compared in order to explore and optimize the comprehensive teaching curricula and system in the university's clinical practice education prior to the South China divisional qualifying match. The most important goals are to promote clinical teaching through the game and to focus on fostering medical students' clinical competence, including clinical thinking, humanistic care, doctor-patient communication skills, emergency management, actual practice, and teamwork in one effective system (Yang 2015). In addition, an outstanding clinical teaching staff team has been built and improved in our college. Accordingly, the aim of this study is to analyze and compare the seven sessions of the clinical skills competition and organization in order to explore an efficient and reasonable training program considering the conditions of our university.

\section{Method}

\subsection{Participants and Setting}

Each year, 6-12 excellent medical students at Jinan University are selected through a theory examination and clinical skills test on diagnostics, internal medicine, surgery, obstetrics and gynecology, and pediatrics, in addition to comprehensive evaluations such as psychological quality and adaptability. There were no significant difference in the average scores between students from each grade. They formed a team as an observation group to participate in this study from 2011 to 2017 to establish a good and scientific training system based on the clinical skills scope and items issued by the Ministry of Education. These students all came from the fourth or fifth year of the 5- or the 6-year clinical medicine major. They had finished all basic and clinical courses according to the teaching plans and had entered the internship period. In addition, the same group of teachers would be in charge of and would undertake the whole training task.

\subsection{Teaching Methods}

2.2.1 To establish training modules and programs based on the requirements and syllabus of the National Clinical Skills Competition

2.2.2 To produce a thoughtful training plan that would cover the 6-9-month period before attending the South China divisional qualifying match held in the southern area of China

2.2.3 To summarize and analyze the general patterns of and changes in the organization of the training course among the 7 sessions

2.2.4 To form a teacher team responsible for the training course. These faculty members consisted of relevant specialists who had extensive clinical and teaching experience

2.2.5 To perform a specific implementation of the training and assessment for each module.

2.2.6 To conduct the formative and cumulative evaluation of the effects of training.

2.2.7 To adopt an optimal training program to prepare for the eighth session of the competition based on the experiences obtained from the analysis and exploration of clinical skills teaching and learning in the previous six matches.

\subsection{Statistic Analysis}

Statistical analyses were performed by using SPSS 17.0 (SPSS Inc., Chicago, Illinois). The correlation between the training hours and qualification for the national final match was analysed by logistic analysis.Two-tailed p-values $<0.05$ were considered statistically significant.

\section{Results}

3.1 Establishment of Training Modules, Items and Programs Based on the National Competition Requirements and Syllabus

Training modules, skills, items and programs illustrated in Table 1. Teaching items of training skills in different session of competitions (prior to the South China divisional qualifying match) illustrated in Table 2 and Figure 1. 
Table 1. List of Training Modules, Skills and Program

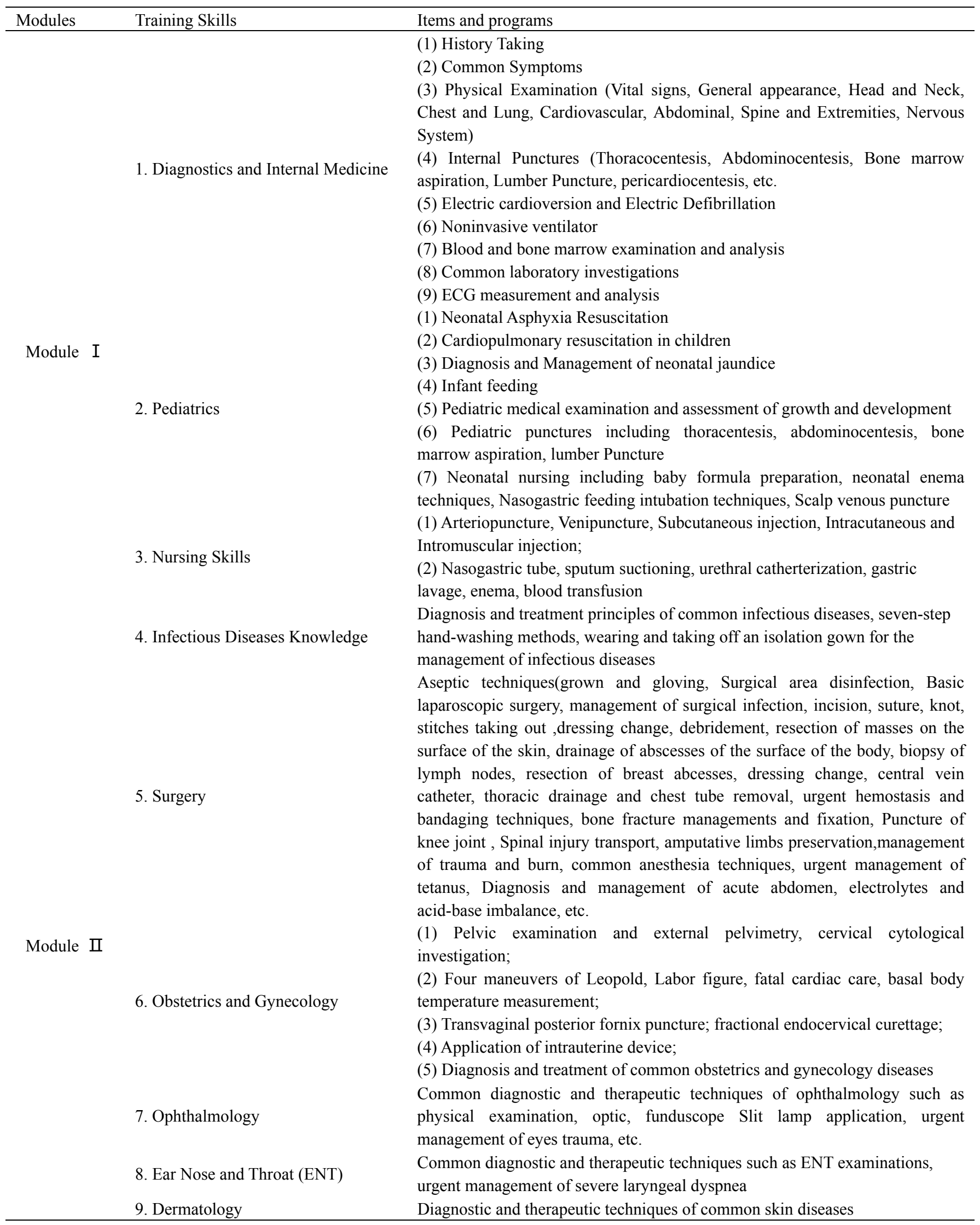


Table 1. List of Training Modules, Skills and Program(continued)

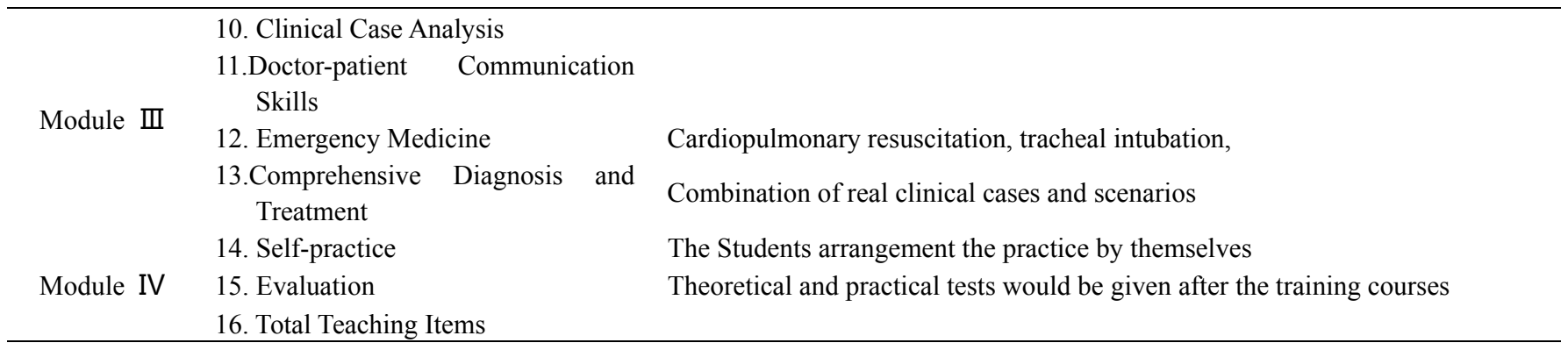

Table 2. Teaching Items of Training Skills in Different Session of Competitions

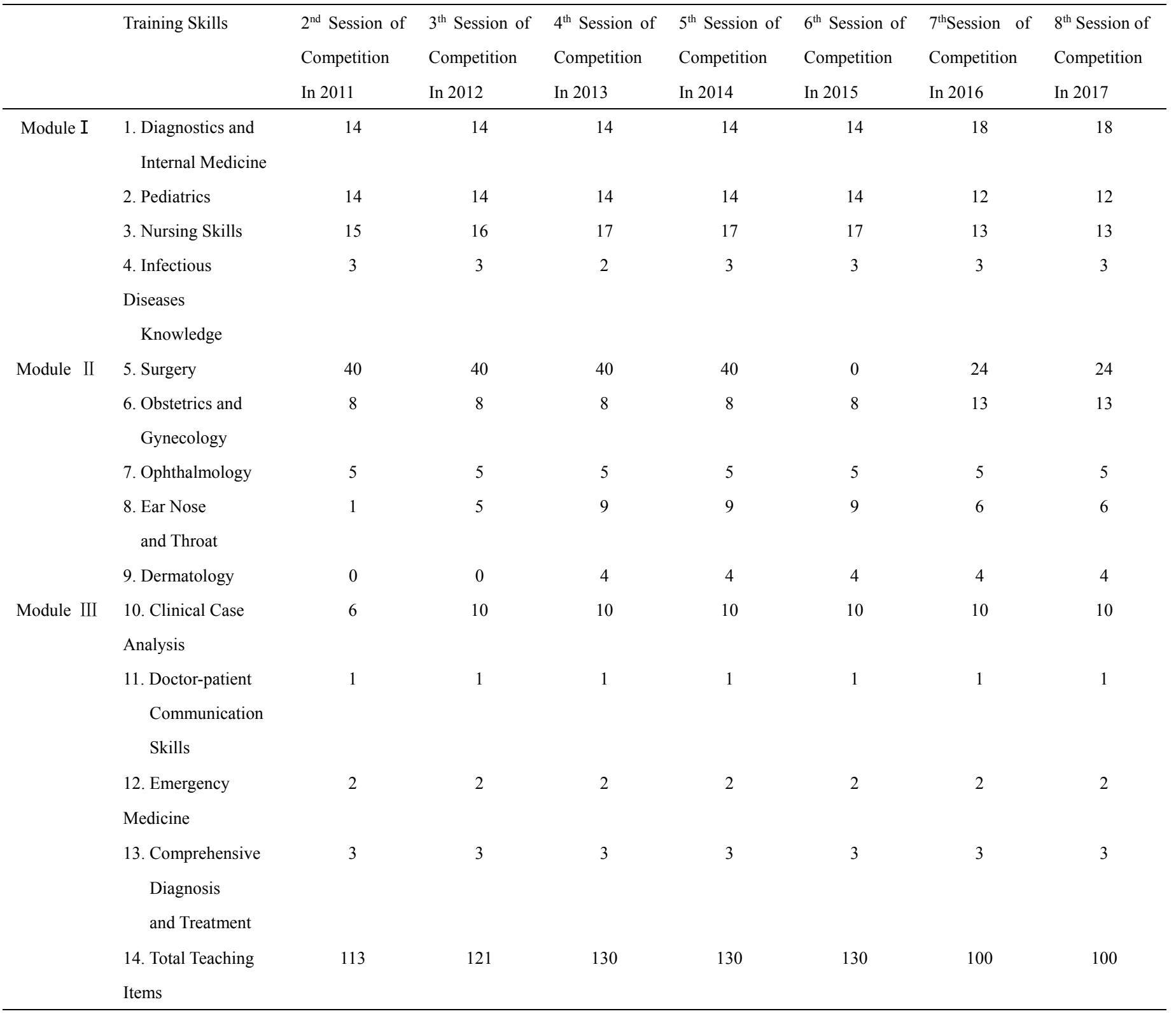


(a)

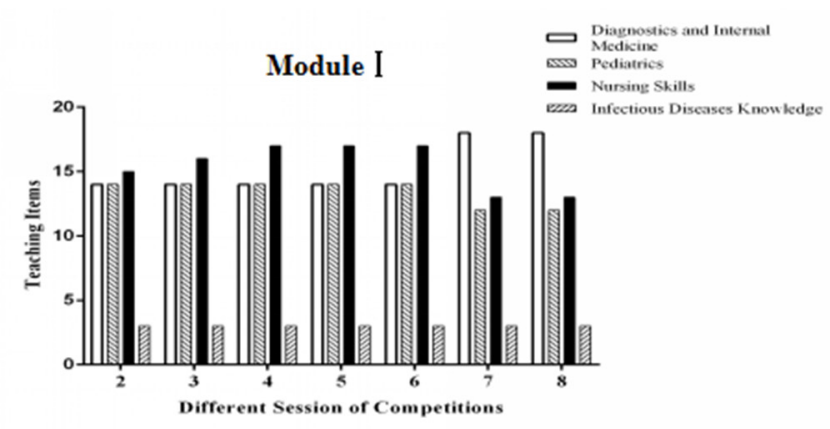

(c)

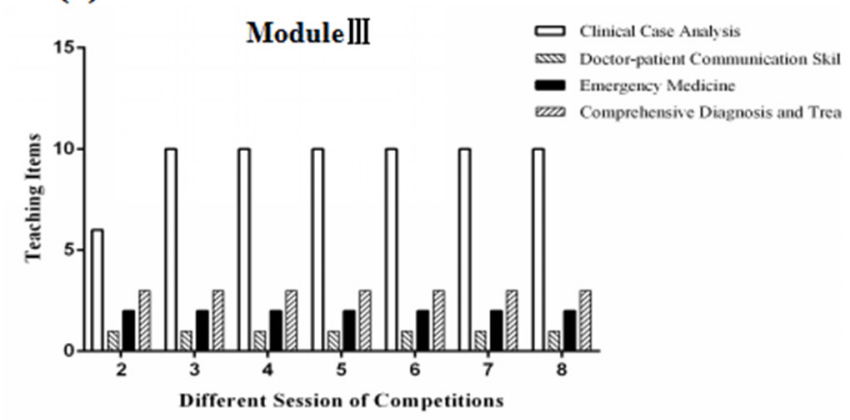

(b)

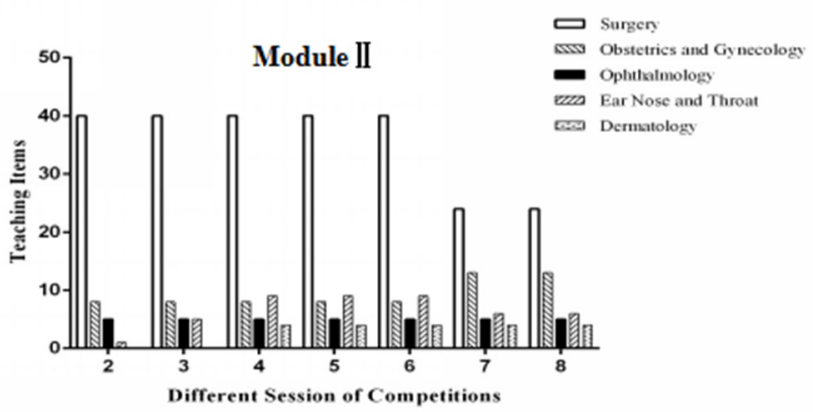

(d)

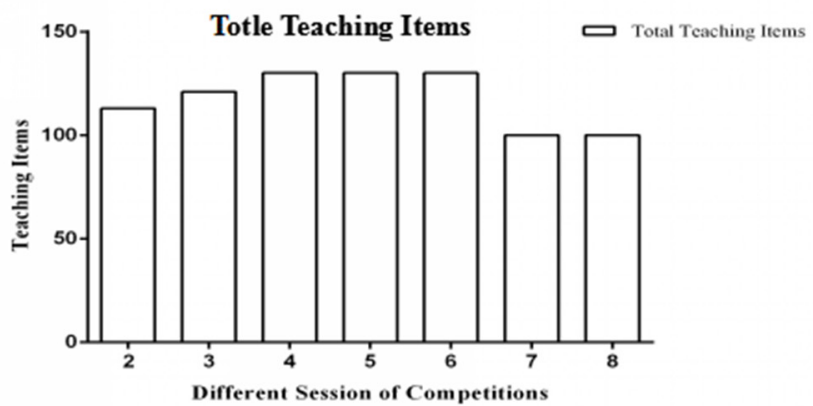

Figure 1. Training Modules, Items and Programs of the Competitions

\subsection{Training Course Organization among the 7 Sessions as Follows}

Teaching hours of the training skills in different session of competitions (prior to the South China divisional qualifying match) illustrated in Table 3 and Figure 2.

Table 3. Teaching Items of Training Skills in Different Session of Competitions

\begin{tabular}{|c|c|c|c|c|c|c|c|c|}
\hline & Training Skills & $\begin{array}{l}2^{\text {nd }} \text { Session of } \\
\text { Competition } \\
\text { In } 2011\end{array}$ & $\begin{array}{l}3^{\text {th }} \text { Session of } \\
\text { Competition } \\
\text { In } 2012\end{array}$ & $\begin{array}{l}4^{\text {th }} \text { Session of } \\
\text { Competition } \\
\text { In } 2013\end{array}$ & $\begin{array}{l}5^{\text {th }} \text { Session of } \\
\text { Competition } \\
\text { In } 2014\end{array}$ & $\begin{array}{l}6^{\text {th }} \text { Session of } \\
\text { Competition } \\
\text { In } 2015\end{array}$ & $\begin{array}{l}7^{\text {th }} \text { Session of } \\
\text { Competition } \\
\text { In } 2016\end{array}$ & $\begin{array}{l}8^{\text {th }} \text { Session of } \\
\text { Competition } \\
\text { In } 2017\end{array}$ \\
\hline \multirow[t]{4}{*}{ Module I } & $\begin{array}{l}\text { 1. Diagnostics and } \\
\text { Internal Medicie }\end{array}$ & 72 & 101.5 & 93 & 71 & 97 & 86 & 91 \\
\hline & 2. Pediatrics & 21 & 27.5 & 26.5 & 28.5 & 49 & 37 & 28 \\
\hline & 3. Nursing Skills & 12 & 18.5 & 40 & 59.5 & 85 & 65 & 42 \\
\hline & $\begin{array}{l}\text { 4. Infectious Diseases } \\
\text { Knowledge }\end{array}$ & 7 & 6 & 2 & 8.5 & 7.5 & 16 & 6 \\
\hline \multirow[t]{5}{*}{ Module II } & 5. Surgery & 68 & 112.5 & 173.5 & 155 & 118.5 & 134 & 130 \\
\hline & $\begin{array}{l}\text { 6. Obstetrics and } \\
\text { Gynecology }\end{array}$ & 21 & 35.5 & 37.5 & 37 & 58 & 36 & 32 \\
\hline & 7. Ophthalmology & 3 & 6 & 15 & 17.5 & 18 & 34 & 16 \\
\hline & $\begin{array}{l}\text { 8. Ear Nose } \\
\text { and Throat }\end{array}$ & 1 & 8.5 & 20.5 & 15.5 & 27 & 20 & 16 \\
\hline & 9. Dermatology & 0 & 0 & 18.5 & 11.5 & 21 & 23 & 16 \\
\hline
\end{tabular}


Table 3. Teaching Items of Training Skills in Different Session of Competitions(continued)

\begin{tabular}{|c|c|c|c|c|c|c|c|c|}
\hline \multirow[t]{4}{*}{ Module III } & $\begin{array}{l}\text { 10. Clinical Case } \\
\text { Analysis }\end{array}$ & 30 & 24 & 41.5 & 35 & 15 & 20 & 8 \\
\hline & $\begin{array}{l}\text { 11.Doctor-patient } \\
\text { Communication } \\
\text { Skills }\end{array}$ & 3 & 3 & 6 & 3 & 1 & 2 & 2 \\
\hline & $\begin{array}{l}\text { 12. Emergency } \\
\text { Medicine }\end{array}$ & 30 & 28.5 & 40 & 59.5 & 85 & 65 & 42 \\
\hline & $\begin{array}{l}\text { 13.Comprehensive } \\
\text { Diagnosis } \\
\text { and Treatment }\end{array}$ & 3 & 5 & 15.5 & 14.5 & 12 & 25 & 48 \\
\hline \multirow[t]{3}{*}{ Module IV } & 14. Self-practice & 63 & 104.5 & 158.5 & 148 & 193.5 & 215 & 100 \\
\hline & 15. Evaluation & 13 & 16.5 & 27.5 & 19 & 68 & 72 & 80 \\
\hline & $\begin{array}{l}\text { 16. Total Teaching } \\
\text { Hours }\end{array}$ & 347 & 497.5 & 715.5 & 664.5 & 822.5 & 830 & 647 \\
\hline
\end{tabular}

(a)

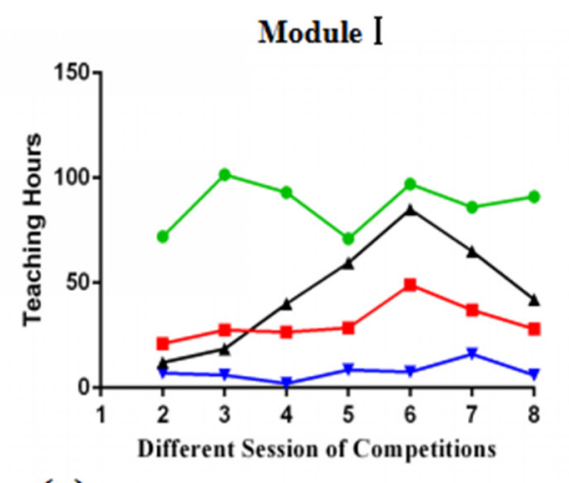

(c)

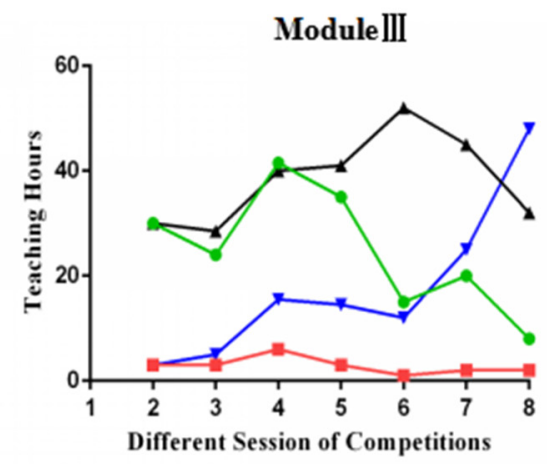

(b)

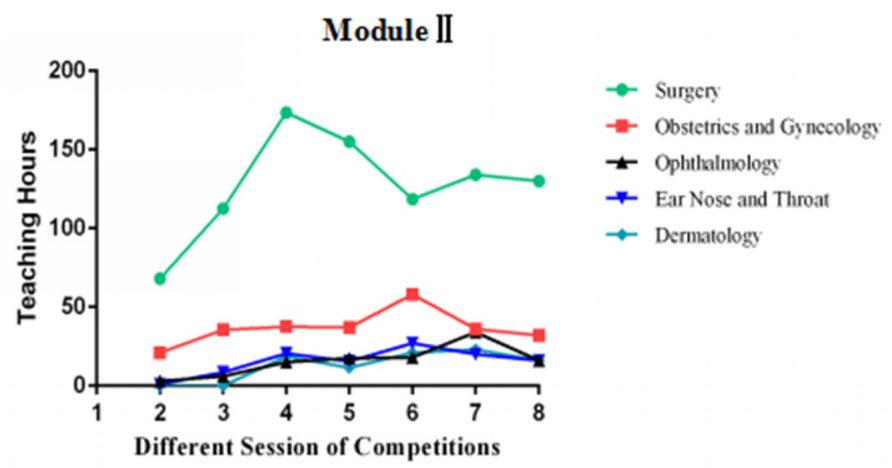

(d)

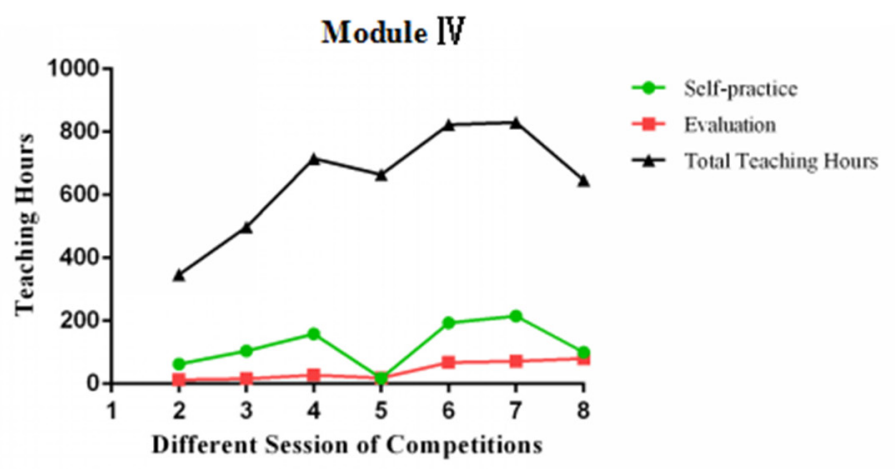

Figure 2. Teaching Hours for the Training Skills in Different Sessions of the Competitio

\subsection{The Correlation between the Training Hours and Qualification for the National Final Match}

The correlation between the training hours and qualification for the national final match was analysed by logistic analysis. The result showed $P=0.887$ and no significance.

3.4 Summation and Analysis of the Changes in the Organization of the Training Course among the 7 Sessions

Summation and analysis of the changes in the organization of the training course among the 7 sessions illustrated in Figure 3. 


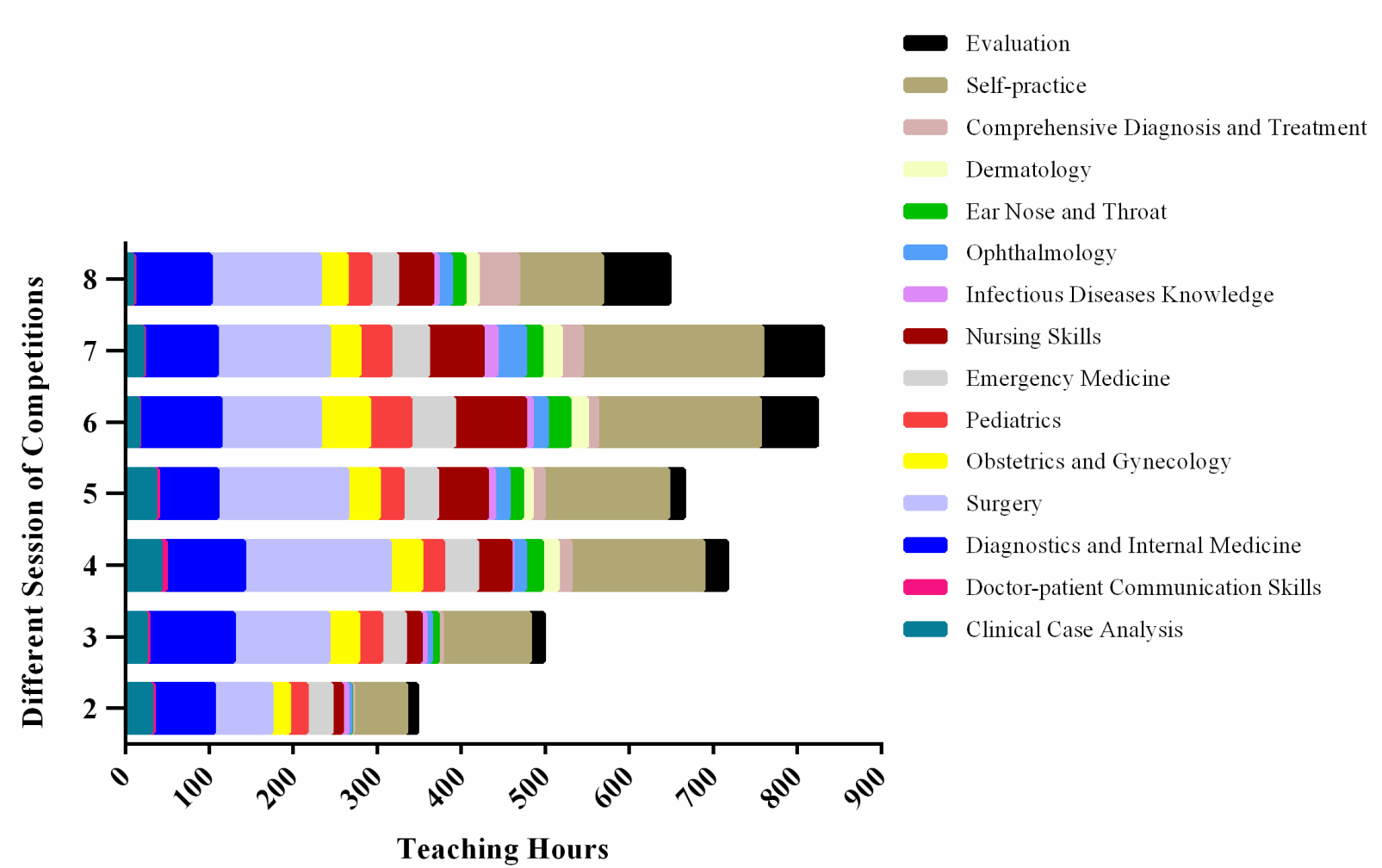

Figure 3. The Training Courses among the 7 Sessions

\subsection{The Seventh Session}

The seventh session was special because the South China regional competition was held at our university. Therefore, the rules and requirements for the clinical skills competition should have been better understood, in addition to the scenarios, clinical cases, evaluation and checklists for each item. Our clinical medicine college organized a specific team including specialists, clinical faculty members, and referees. They were responsible for the preparation and verification of clinical cases, the design of the scenario, the application of simulators, the evaluation checklists, etc.

\subsubsection{Example of Practical Items and Techniques-Clinical Information and Requirements}

A 28-year-old male presented with left chest pain with low fever and night sweats for 3 days. PE at admission: $\mathrm{T}$ $37.8^{\circ} \mathrm{C}$, P $80 \mathrm{bpm}, \mathrm{R} 19$ cycles/min, BP $115 / 78 \mathrm{mmHg}$. No tracheal deviation. Left chest full, and widening of the intercostal space observed. Thoracic expansion and tactile fremitus decreased at the left lung palpation. Dullness of the percussion note found in the left lung. In the auscultation of the lung, the breath sounds disappeared, and vocal conduction decreased in the left side. No significant findings in the right lung examination. Heart examination normal. PPD skin test $(+++)$ in out-patient clinic. Now, please give a further evaluation and appropriate management for this patient.

3.5.2 Checklist for the Thoracentesis Scenario Test

Checklist for the thoracentesis scenario test was illustrated in Table 4. 
Table 4. Checklist for the Thoracentesis Scenario Test (Chen 2013)

\begin{tabular}{|c|c|c|}
\hline Main Steps & Items and Evaluation & Standard Score \\
\hline \multirow{12}{*}{ Preparatory work } & 1. Comfirmation of Patient identification & 1 \\
\hline & 2. Explain the purpose and main steps to the patient & 1 \\
\hline & 3. Inform the remarks & 1 \\
\hline & 4. Wash hands & 1 \\
\hline & 5. Check vital signs & 1 \\
\hline & 6. Review blood routine examination & 1 \\
\hline & $\begin{array}{l}\text { 7. Obtain consent from the patient and family members. } \\
\text { Finish the operation agreement form }\end{array}$ & 1 \\
\hline & 8. Inquire allergic history to anesthesia again & 1 \\
\hline & 9. Percussion of two lungs & 1 \\
\hline & 10. Auscultation of two lungs & 1 \\
\hline & 11. Verify imaging results such X-ray, ultrasonography & 5 \\
\hline & $\begin{array}{l}\text { 12. Prepare the appropriate packages, instruments, all } \\
\text { materials and drugs needed such as skin disinfectant, local } \\
\text { anesthetic, rescue medicines, etc. }\end{array}$ & 1 \\
\hline \multirow{4}{*}{$\begin{array}{l}\text { Determining patient position and } \\
\text { puncture site }\end{array}$} & 13. Set appropriate position for the patient & 1 \\
\hline & 14. Select the correct puncture site & 1 \\
\hline & 15. Mark the puncture site clearly & 1 \\
\hline & $\begin{array}{l}\text { 16. Give local disinfection of the puncture site by Anerdian } \\
\text { for 2-3 times. Disinfection order and scope should be } \\
\text { performed in a concentric circles sequence from the center } \\
\text { outward, diameter of the disinfection area at least } 15 \mathrm{~cm} \text {. }\end{array}$ & 2 \\
\hline \multirow{5}{*}{$\begin{array}{l}\text { Disinfection of the puncture area, } \\
\text { check and open the package }\end{array}$} & 17. Check valid date of the package, open the outer layer & 1 \\
\hline & 18. Wear sterile gloves carefully & 1 \\
\hline & $\begin{array}{l}\text { 19. Open the inner layer of the package, and check the } \\
\text { materials whether complete }\end{array}$ & 2 \\
\hline & 20. Check the patency of the large puncture needle & 2 \\
\hline & 21. Place the surgical drape accordingly & 2 \\
\hline \multirow[t]{5}{*}{$\begin{array}{l}\text { Infiltration of the puncture site } \\
\text { from the skin to pleura }\end{array}$} & $\begin{array}{l}\text { 22. Check the drug name, valid date of } 2 \% \text { lidocain. And take } \\
3-5 \mathrm{ml} \text { of lidocain for local anesthesia. }\end{array}$ & 5 \\
\hline & 23. Infiltrate anesthesia from the skin to the pleura & 3 \\
\hline & $\begin{array}{l}\text { 24. Ensure the needle of the syringe no enter the blood } \\
\text { vessles }\end{array}$ & 3 \\
\hline & $\begin{array}{l}\text { 25. Clamp the rubber tube which has been connected to the } \\
\text { large needle }\end{array}$ & 3 \\
\hline & $\begin{array}{l}\text { 26. Large needle with clamped rubber tube should be } \\
\text { directed over the superior margin of the rib to pleura, slowly } \\
\text { advanced into the pleural cavity }\end{array}$ & 5 \\
\hline \multirow{7}{*}{$\begin{array}{l}\text { Needle penetration and specimen } \\
\text { collection }\end{array}$} & $\begin{array}{l}\text { 27. Obtain pleural fluid which will be transferred to the lab } \\
\text { for further evaluation }\end{array}$ & 12 \\
\hline & 28. Bacterial culture & 1 \\
\hline & 29. Mycobacterial culture & 2 \\
\hline & 30. Routine examination & 2 \\
\hline & 31. Biochemistry and enzymatic examination & 2 \\
\hline & 32. Pathological examination & 1 \\
\hline & 33. Mark the tubes and bottles & 1 \\
\hline
\end{tabular}


34. Clamped the tube again after the collection of the samples finished

35. Press for 1-2 minutes of the puncture site by sterile gauze

Post-Procedure

Professionalism, Concept and procedures related to disinfection; Observing pt illness during the whole process; Team work and cooperation spirit

Answering the relevant questions

Total Mark after the needle withdrawal and puncture area disinfection again

36. Puncture area disinfection

37. Cover sterile gauze and the wound fixed by adhesive plaster

2

38. Inform post-operative precautions

3

39. Observe the patient illness and check vital signs 2

1

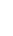

40. Pay attention to protect patient privacy 2

41. Patient-oriented 2

42. Proficiency in the whole operation 2

43. Team-work 2

44. Make an accurate diagnosis and choose correct
treatments

Note: The training items were determined according to the scope of the national competition and the specific circumstances of the clinical medicine college.

3.6 An Excellent Interdisciplinary Teacher Team was Formed and was Responsible for the Main Training Task. These Faculty Members Consisted of Relevant Specialists Who Had Extensive Clinical and Teaching Experience

To conduct the clinical skill training program, a teacher team was formed who integrated scientific management and teaching implementation. The members of this team were from the main clinical departments such as internal medicine, surgery, obstetrics and gynecology, pediatrics and other relevant departments. They were accomplished in medical, teaching and scientific studies. They were enthusiastic with regard to teaching and innovation; in particular, they eagerly explored an updated pedagogy that could help to improve the professional ethics of medical students including the personnel training mode, teaching methods, evaluation methods, and other aspects of continuous exploration and research, and they made gratifying achievements. These team members undertook research and implementation in the clinical training center and teaching hospital. They developed standard approaches to clinical skills, collected clinical cases, established the teaching plan, designed the pedagogy, and assessed student proficiency. During the whole process, the team faculty members played an important role in enhancing the comprehension level of students regarding the clinical management of different cases and students' practical ability (Liu 2013). At the same time, a variety of teaching methods, such as teaching rounds and teaching case discussions in the hospital as well as online network teaching were adopted to promote the implementation of the course. Interdisciplinary case discussions were explored, and case-based learning (CBL), problem-based learning (PBL), and team-based learning (TBL) were applied during training process in order to strengthen the students' clinical thinking ability in clinical diagnosis and treatment related to clinical decision making. This study can also encourage young doctors and teachers to participate in the training program to ensure the sustainable development of the teaching team. The team was constantly summarizing and analyzing their teaching effects, collecting teaching cases, and writing specific practical teaching materials that could be used at various levels of teaching in undergraduate, graduate, and resident education. Moreover, the team achieved a good place in the South China regional competition and in the final matches of the National Clinical Skills Competition, consequently providing excellent guidance to the medical students.

\subsection{Specific Implementation of the Training and Assessment Process Aim at Enhancing Clinical Competence}

\subsubsection{Diagnostics and Internal Medicine Section}

(a) Basic Arrangement of the Diagnostics and Internal Medicine Section

For history taking and physical examination skills training, standardized patient (SP) scenarios based on simulator 
and real clinical cases can be used to cultivate doctor-patient communication, humanistic care, and systemic and accurate procedural techniques. In addition, practical classes in internal punctures including thoracocentesis, abdominocentesis, bone marrow aspiration, and lumbar puncture were ingeniously designed in combination with the fundamental concepts of indications and contraindications in the clinical scene. The students were required to make a judgment accurately by clinical thinking. Otherwise, they would make serious mistakes because the training scenarios were full of "traps".

(b) Example of Practical Items, Techniques and Scenarios in Training and Competition

Scenario 1, a 30-year-old male presented with recurrent fever, chest discomfort and cough for one month; after five days of headache and vomiting, he was admitted to the hospital. Please take a history from him and perform a focused physical examination within 20 minutes.

Scenario 2, a 30-year-old male presented with recurrent fever, chest discomfort and cough for one month; after five days of headache and vomiting, he was admitted to the hospital. The patient had a ten-year history of smoking, at a rate of one pack per day.

PE, T $38.5^{\circ}$ C, P 92 bpm, R 23 cycles / min, BP 130/80 mmHg. Active position. State of confusion.

No cyanosis of the skin and mucus. Two pupils $3.0 \mathrm{~mm}$ in diameter, round and bilaterally symmetric with an acute response to light. The bilateral optic papilla border was not clear, but no obvious fundus hemorrhage. No three depression signs. Tactile fremitus decreased, dullness of the percussion note was found, and a few crackles were heard in the right lower part of the lung. No significant findings of the heart and the abdomen. Neck rigidity, Kernig sign and Brudzinski sign were positive. No significant findings in the resting nervous system examination.

Laboratory investigations showed that the blood, urine and stool routine examinations were normal. Liver and kidney function tests were normal. Chest X- ray showed a small amount of pleural effusion in the right lower lung. Please give a further evaluation and appropriate management.

\subsubsection{Surgical Section}

(a) Basic Arrangement of the Surgical Section

The surgical training and assessment system focused on the strict aseptic concept and approaches; basic surgical skills; the management of infection and urgent surgical situations; the assessment, timing and sequence of contaminated or clear wound dressing and removal of stitches; and basic orthopedic skills. The students were required to have a strong aseptic concept and to master surgical management principles well. Furthermore, training should have been conducted on common clinical scenarios related to surgical conditions, such as inguinal hernia surgery area disinfection, surgical drape on the right upper abdomen incision site, wearing a gown, the removal of stitches from an abdominal wound and dressing, gastrointestinal lateral anastomosis, plaster external fixation of a forearm fracture, the emergency management of tension pneumothorax, lower limb hemorrhage treatment, etc.

(b) Example of Practical Items, Techniques and Scenarios in Training and Competition

Scenario 1: A 30-year-old male; 3 hours before admission, when he was working in the fields, he was struck by a hoe, and his back was injured. He just used cloth to do a simple bandaging, and now he has come to the hospital for emergency treatment. Please treat the patient correctly.

Scenario 2: A 20-year-old male, presenting with increasing purulent secretion 2 days after abscess incision due to abdominal wall infection and abscess in the skin at admission. Please give the correct treatment for this patient.

Scenario 3: One injured person was rescued in a traffic accident that occurred on the highway. Emergency medical technicians were called and arrived immediately by ambulance. The injured was a 34-year-old male, presenting with dizziness, shortness of breath, and slight left upper abdominal pain. In the physical examination, the patient was well-oriented. One $5 \mathrm{~cm}$ wound with a fracture end was found in the middle section of the right lower limb. Active bleeding was also observed inside the wound. He felt leg pain and could not even move. Activity, sensation, and the blood supply of each toe were good in the right foot. No wounds found in the two upper extremities or the left lower extremity. Please give the appropriate evaluation and management immediately on the scene.

\subsubsection{Obstetrics and Gynecology, and Pediatrics Section}

(a) Basic Arrangement of the Obstetrics and Gynecology and Pediatrics Section

It was also necessary to seriously train on the items and basic skills in obstetrics and gynecology, as well as on the pediatrics department due to their unique patients who need more concerns and better doctor-patient communication techniques. The training skills included neonatal umbilical treatment, diagnostic curettage surgery, transvaginal 
posterior fornix puncture, neonatal asphyxia resuscitation, cardiopulmonary resuscitation in children, infant feeding, pediatric medical examination and the assessment of growth and development, common pediatric punctures, and neonatal nursing skills. These projects are conducted in the teaching process; there are only a few opportunities for students to operate due to specific considerations of patient safety.

Accordingly, the courses could only be practiced and repeated in the simulation center at first. The students were organized to enter the ward and to learn how to manage real cases under the guidance of the supervisors in order to improve their ability to rapidly respond to a changing situation and to quickly establish an accurate diagnosis plan.

(b) Example of Practical Items, Techniques and Scenarios in Training and Competition.

Scenario 1: A 54-year-old female presenting irregular vaginal bleeding for one month, 5 years after menopause. Please perform fractional endocervical curettage in order to make an accurate diagnosis.

Scenario 2: One male baby, the first of three fetuses delivered by urgent cesarean section with a gestational age of 37 weeks. His mother suffered from gestational hypertension and severe preeclampsia. The mother was given diazepam and magnesium sulfate before delivery. Antenatal fetal heart rate was maintained at $142-150 / \mathrm{min}$, and the variation was poor. At birth, the amniotic fluid was clear, the baby's skin had a generalized pallor, and the extremities were soft; no crying or breathing found. The following management was given immediately: keeping warm by radiation station, adjusting his position, cleaning up the respiratory tract, drying his skin, stimulating the feet for approximately 30 seconds, HR $50 \mathrm{bpm}$. How are the Apgar scores determined, and how is a primary diagnosis made? How will this infant be rescued?

\subsubsection{Ophthalmology, Otorhinolaryngology, and Dermatology Section}

(a) Basic Arrangement of the Ophthalmology, Otorhinolaryngology, and Dermatology Section

Training was also given in fundamental skills in ophthalmology, otorhinolaryngology, and dermatology in the program such as optic funduscope, a routine ENT examination, the urgent management of severe laryngeal dyspnea, and diagnostic and therapeutic techniques of common skin diseases. In the early stage, basic points were taught and learned; then, increasingly more specialized skills could be introduced in combination with clinical conditions.

(b) Example of Practical Items, Techniques and Scenarios in Training and Competition

Scenario 1: A 23-year-old male presents with right eye pain and a decrease in visual acuity for 1 hour after being hit by a baseball in this eye. Please give the correct evaluation and management.

Scenario 2: A 40-year-old male has presented with hoarseness for six months, aggravated by dyspnea for 10 days. PE, respiratory dyspnea with four depression signs found. Generalized sweating. Blood oxygen saturation $\mathrm{SaO} 2<80 \%$. III-IV degree dyspnea. Please provide urgent thyrocricocentesis to relieve the patient's dyspnea.

Scenario 3: A 44-year-old female has presented with facial rashes and itching for 14 years, with no fever, headache, etc. In addition, the rashes became aggravated and expanded to the upper limbs, chest and abdomen area 3 months ago. In her past medical history, she had long-term facial nursing care. PE, diffuse macules with slight edema and obvious desquamation found on her face. How is a management plan made for this patient?

\subsubsection{Comprehensive Diagnosis and Treatment Section}

The comprehensive diagnosis and treatment section training emphasized the spirit of teamwork, clinical thinking capacities, decision-making ability, and practical performance. It represents an important shift from basic skills to more complex management. This section should check and evaluate the students in regard to how to combine the theoretical knowledge learned and the real practical techniques in order to solve a clinical problem effectively and ultimately improve the overall level of diagnosis and treatment. First they practiced on the simulators and gradually learned more in the hospitals and upgraded their clinical competency (Issenberg 2005).

Example of practical items and techniques:

A 52-year-old male presented with sudden and continuous precordial crushing chest pain accompanied by a cold sweat for six hours and was sent to our hospital. ECG showed acute myocardial infarction of the extensive anterior wall. Serum cardiac enzymes and myocardial necrosis markers were confirmed increased. The student team was required to give an urgent diagnosis and treatment. The whole process involved many clinical skills including history taking, physical examination, doctor-patient communication, analysis of the previous ECG and lab results, and the establishment and determination of the primary diagnosis and treatment. Many difficult clinical problems needed to be considered, and decisions had to be made such as how to choose the myocardial reperfusion methods for this case, how to manage the complications of severe arrhythmias, heart failure, or even cardiac arrest, and how to select the 
appropriate drugs to relieve the symptoms and signs. The challenges for the team required completing more than ten operation techniques including the assessment and diagnosis of the illness progression, the observation of vital signs, ECG monitoring, wound hemostasis and bandaging, oxygen therapy, cardiopulmonary resuscitation, tracheal intubation, electric defibrillation, venipuncture and arteriopuncture, intravenous infusion, and urethral catheterization. This case was extremely helpful for cultivating the students' comprehensive diagnosis and treatment abilities and in laying a solid foundation for future clinical work as well.

\subsection{The Comprehensive Evaluations of the Training Effects}

In the course of teaching, the comprehensive evaluations of the training effects consisted of formative and cumulative evaluations (McGaghie 2014; McGaghie 2009). They included a sectional tests, simulation game, the analysis of students' performance and mastery of the clinical skills training, feedback, reflections, and suggestions from teachers and students after each examination or match, and the final competition result. Out of seven sessions, the national final matches were entered five times. The discussion and analysis of the clinical skills details and the competition requirements among the students and teachers focused on whether the teaching plans, syllabus, scenarios, examination cases, checklists for techniques, and the percentage of student self-study hours and evaluation hours were reasonable or not and whether any improvements were needed.

\subsection{The Result of the Eighth Regional Session}

For the eighth session, the lowest number of teaching hours were taken because training was being conducted for similar clinical skill items and the teaching effects were satisfactory given that the optimal training program had been adopted in accordance with the exploration and analysis of participant experiences from the second to sixth sessions, while the seventh session involved holding the South China regional competition. The result of the eighth regional session was successfully entering the national final competition, and a relatively stable teaching system had gradually been formed.

\section{Discussion}

Each year, the scope of the National Clinical Skills Competition is slightly different; however, the content and requirements for medical undergraduates majoring in clinical medicine are basically the same. As the study progressed, the items, related specialties, and involved teachers gradually became the same for the total set of items, starting from 113, then moving to 130, and becoming fixed at 100. This result may be helpful for analysis and research on the assessment and exploration of comprehensive clinical skills training curricula.

4.1 From the second to the Eighth Sessions, the Teaching Hours Needed for Each Section Were Nearly Steady and Consistent; the Exceptions Included the Following

\subsubsection{Nursing Section}

The simple nursing skills training had taken the highest number of teaching hours (85) at the 6th session and was decreased afterwards because these teaching hours had been subsequently integrated into the comprehensive diagnosis and treatment scenarios. In this case, the training was closer to real clinical situations.

\subsubsection{Surgical Section}

There was high fluctuation in the surgical organization mainly because the students had weak related skills. Usually, surgical skills cannot be mastered in a short period of time. Detailed regulations might be implemented according to students' performance. Therefore, it was extremely important to determine the progression and to give feedback on the students' mastery of the techniques in each stage.

\subsubsection{Clinical Case Analysis, Comprehensive Diagnosis and Treatment Section}

Although the teaching hours of the former decreased while those of the latter increased, in this study, it was more helpful to train the students' clinical competence through a comprehensive diagnostic and therapeutic process on the simulator or using clinical cases than by theoretical case studies alone. Clinical thinking and diagnosis and treatment integration were better. The implication is that the combination of clinical thinking and hands-on operation is more effective. And teaching assessments should be carried out continuously.

\subsubsection{Total Training Hours}

Total training hours were gradually increased with the increase in training items. The highest number of hours (830) in the seventh session occurred because our university hosted the South China regional competition, and more teaching hours were applied to test the related competition scenarios. In the sixth session, the result of the regional 
competition was that the team did not enter the final national competition even though the second highest number of teaching hours (823) was taken. It also suggested that was not the more teaching hours, then better effects obtained. The main reason for this result was that the student team's attitude and cooperation had not been analyzed and did not receive better attention. This point may be a lesson in what needed improvement in the subsequent teaching. Ultimately, a reasonable program with average teaching hours was explored and implemented in the eighth session. Satisfactory effects had been achieved, and the most efficient training plan had also been demonstrated in this research.

\subsubsection{The Correlation between Training Hours and Entering National Final Match}

The correlation between training hours and qualifying for the finals was analyzed, and significance was not found. This result simply showed that it is not true that the more hours that are spent on training, the better the results; it also showed that reasonable arrangements should be made and would be more helpful. In addition, the results showed that the training evaluation of comprehensive clinical competence not only relied on the competition results but also needed an analysis of influencing factors from students and teachers, a reasonable organization of lectures, a practical class in the simulator center or hospital, self-study, sectional evaluation tests, etc.

4.2 This Study Involved a Total of 8 National Competitions from 2011 to 2017, and a Large Amount of Clinical and Teaching Experience Helpful for the Achievement of the Final Goal of Clinical Competence Training and Clinical Education Has been Accumulated

\subsubsection{Clinical Thinking and Decision-Making Ability Are the Key-Points and Difficulties in Clinical Skills Training}

In clinical practice, diagnosis of the disease is the most basic skill for medical students and doctors. Only accurate diagnoses can lead to the correct treatments. Clinical teachers should emphasize and guide students to learn the correct principles of clinical thinking in every medical education activity and to bind them tightly to clinical practice(McGaghie 2014). Starting in clinical basic courses such as diagnostics, general surgery, and medical imaging, preliminary clinical thinking rules should be taught because a long-term effort is needed for the enhancement of students' medical skills and the achievement of mastery. This study provides the basis and the reference for curriculum planning. Comprehensive clinical thinking reflects the ability to make an accurate diagnosis, think about differential diagnoses, choose a treatment, and solve specific clinical problems by analyzing clinical information including clinical manifestations and assistant examinations based on the significant diagnostic evidence and therapeutic rules (Sun 2012).

Accordingly, practical teaching must be close to clinical situations. While National Clinical Skills Competitions have provided a very good chance and platform for medical faculties to explore and practice the updated pedagogy and to perfect routine teaching tasks, in the preparation process for this match, pedagogy transformed from the previous teaching methods of "lectures + simple skill operation exercises" to the new mode of "small lectures + procedure training + comprehensive scenarios practice + video retrospective analysis discussion"( Sun, Qin \& Wang 2005; Harris 2010; Sun, Liu \& Shi 2010; McLaughlin, Doezema \& Sklar 2002). Students' clinical thinking ability can be cultivated from different perspectives and directions. This mode can help students to effectively address complicated clinical problems in the future. In the whole study and performance of this practical program, simultaneous training should be received on clinical thinking and decision-making ability, excellent psychological qualities and adaptability, the aseptic concept and operation, the spirit of team cooperation and humanistic care (Issenberg 1999).

4.2.2 For Invasive Operations, the Establishment of Strict Aseptic Concepts Should Run Through all Relevant Procedures in Order to Ensure Clinical Teaching Quality

Medical students should be trained in not only the steps of each skill but also disinfection technology through the practical study, as this has a vital influence on the level and quality of clinical medical work (Hu, Feng \& Chen 2012). Aseptic concepts involve the operation of surgery, obstetrics and gynecology, internal medicine, nursing, emergency medicine and other disciplines. Aseptic technologies include washing hands, wearing surgical clothing, wearing sterile gloves, surgical area skin disinfection, and the surgical drape. In fact, all invasive skills of different specialties would be involved. Only when the essentials of disinfection knowledge and techniques have been mastered can clinical operation be performed perfectly and harm to the patient be avoided. Clinical teachers should focus on and teach students to pay more attention to details such as wearing sterile gloves, keeping the disinfection scope firmly in mind, the sequence of internal and external disinfection, the procedures for entering the operating theater, awareness of the aseptic or contaminated area, the correct way to check and open surgical packages, and the appropriate selection of disinfection solutions. In the conditions of the teaching hospital permit, students could be organized to observe or assist in the real surgical scene to enable them to gradually develop good habits and manners for 
consciously abiding by aseptic principles.

\subsubsection{In Clinical Practical Teaching and Learning, the Spirit of Teamwork and Cooperation Are Also Important}

Team cooperation is not about relinquishing individuality but about giving each team member enough development space. In the process of clinical skills training, TBL and individualized teaching should be reasonably applied to improve students' communication skills and cooperation ability and to play to their potential or advantages. In addition, the curriculum should be designed according to students' aptitude and to ensure a better effect from training. Therefore, for this study, some teaching hours may have detailed regulations based on the students' performance and characteristics as part of the basis of the whole training system. It is also necessary to train students in humanistic care and professionalism. In clinical practice, humanistic care can reflect the doctor's sympathy and concern for patients, which is helpful in relieving the patients' illness. Therefore, an excellent humanistic quality is essential for the medical student to grow to be an outstanding doctor on the basis of mastering clinical knowledge and skills (Zhao, Dai \& Fan 2011). In fact, humanistic care education should be involved in many aspects in the hospital, including doctor-patient communication skills, history taking, physical examination, operation or techniques, observation of patients' illness, and making and carrying out relevant treatments. All this needs to be organized in the competition preparation and in the routine program. A patient orientation and patient safety considerations should be taken seriously as well. In addition, good medical ethics and good doctor manners should be carefully fostered. During the teaching and learning process, the teacher and students also need to be aware of any aspects of diagnosis and treatment that may be harmful to the patient and try their best to avoid them.

The established curriculum also needs to train students to have good psychological qualities and adaptability. The skills to deal with complicated clinical events can only be improved based on long-term study and hard work in clinical practical training to develop rapid and appropriate judgment and management in urgent or critically ill conditions such as cardiac arrest, dyspnea or apnea, shock, massive internal hemorrhage, acute poisoning, or multiple organ failure. How to keep calm in an emergency, think about the diagnosis and treatment strategies, and correctly carry out effective treatments to save the patient's life - all this is the main task and effort of doctors and medical students.

In short, the course settings and the schedule should be studied and analyzed carefully and seriously. Sectional evaluation, feedback, and research on training effects should be carried out continuously in order to refine and quantify the clinical skills training objectives. The accumulation of experience and practice can be extended to all clinical practical education in the university.

\section{Conclusion}

The clinical skill competition provided a good platform for medical colleges and universities to exchange teaching methods and promote practical clinical teaching and learning. However, clinical skills training is specialized, interdisciplinary and diverse. During this process, one reasonable and scientific curriculum system involving the main clinical specialties and common diagnostic and therapeutic skills can be explored and established. It is crucial to have a deliberate design. The optimal organization should be studied and created considering and combining the following aspects: the national competition content, the decomposition of items by our college, the total teaching hours, the percentage of every specialty involved in professional ethics, theory, practice, basic skills, clinical scenarios, real cases, and the sectional evaluation. In addition, the schedule should be regulated flexibly based on the analysis of students' weaknesses and degree of mastery and the teachers' experience and suggestions. In addition, it is also necessary to observe and follow up on students' team attitude and cooperation. The strongest feelings and experience were that clinical skills should be trained and examined effectively and repeatedly in order to increase the comprehensive capacities of medical students. Meanwhile, a team of excellent teachers who were responsible for the entire training task was cultivated. In short, curriculum construction and team building were formed synchronously through the National Clinical Skills Competition. Careful exploration and research can perfect training.

\section{Limitations and Future Directions}

The National Clinical Skills Competition is held each year, and the match items related to many students, teachers, and specialties were complicated. Accordingly, as a result, the influencing factors are diverse. It is difficult to control for all of them(Yang 2013). This study can only focus on the discussion and analysis of the relatively rational arrangement and implementation of comprehensive clinical skills training so as to find general rules in a practical clinical teaching methodology. Next, more standard training and the introduction of more clinical situations should be carried out. In addition, the teaching and learning experiences will be summarized and promoted to undergraduate 
education in our clinical medicine college.

\section{Acknowledgements}

The authors would like to thank all of the teachers and medical students who participated in this study. We appreciated the help of Anding Xu, Jingxiang Zhong, Wei Chang, Yueping Liu, Yanghai Zhou, Yuhong Wen, Hanlin Tang, Huaxi Wang, Haizhi Liu, Xiaopin Wang, Yalan Li, Qinran Lin, Mingya Zhang, Guohua Huang, Jinai He, Jieruo Li, Rijia Zhang, Xiuxian Lin, Lliyun Zhu, Dongdong Zhang, Min Yi, Wuan Zhou, Quan Zhou, Xiaoming Chen, Yuhong Lu, Huilan Zeng, Jianfan Chen, Fang Yang and Bingxiao Li from the first affiliated hospital of Jinan University, as well as Jun Dong and Renbin Qi from medical department of Jinan University.

\section{References}

Chen, W.P., Pan, X.L., Wang, X.H., Lu, X.F., Liu, C.Y., Hu, S.J., Kang, X.X., \& Yang, J. (2013). Diagbostics. The ' $12^{\text {th }}$ Five-Year' National Planning Textbooks of Higher Education. PEOPLE'S MEDICAL PUBLISHING HOURSE, CHINA. the $8^{\text {th }}$ edition: 590-591.

Harris, P., Snell, L., Talbot, M., \& Harden, R. M. (2010). Competency-based medical education: implications for undergraduate programs. Med Teach, 32(8), 646-650. https://doi.org/10.3109/0142159X.2010.500703

Hu JF., Feng B., \& Chen A. (2012). Strengthening Surgical Aseptic Technique and Cultivating Qualified Medical Students. J Med Theor \& Prac, 25(4), 482-483.

Issenberg SB., McGaghie WC., Hart IR., Mayer JW., Felner JM., Petrusa ER., Waugh RA., Brown DD., Safford RR., Gessner IH., Gordon DL., \& Ewy GA. (1999). Simulation technology for health care professional skills training and assessment. JAMA, 282(9), 861-866. https://doi.org/10.1001/jama.282.9.861

Issenberg SB., McGaghie WC., Petrusa ER., Lee GD., \& Scalese RJ. (2005). Features and uses of high-fidelity medical simulations that lead to effective learning: a BEME systematic review. Med Teach, 27(1), 10-28. https://doi.org/10.1080/01421590500046924

Jiang G., Chen H., Wang Q., Chi B., He Q., Xiao H., Zhou Q., Liu J., \& Wang S. (2016). National Clinical Skills Competition: an effective simulation-based method to improve undergraduate medical education in China. Med Educ Online, 21(1), 29889. https://doi.org/10.3402/meo.v21.29889

Liu D., Meng X., Su H., \& S W. (2013). Promoting effect of national clinical skills competition for medical students on their cultivation. China Higher Medical Education, 20-21.

McGaghie WC., Siddall VJ., Mazmanian PE., \& Myers J. (2009). Lessons for continuing medical education from simulation research in undergraduate and graduate medical education: effectiveness of continuing medical education: American College of Chest Physicians Evidence-Based Educational Guidelines. Chest, 135(3), 62S-68S. https://doi.org/10.1378/chest.08-2521

McGaghie, WC., Issenberg, S. B., Barsuk, J. H., \& Wayne, D. B. (2014). A critical review of simulation-based mastery learning with translational outcomes. Med Educ, 48(4), 375-385. https://doi.org/10.1111/medu.12391

McLaughlin SA., Doezema D., \& Sklar DP. (2002). Human simulation in emergency medicine training: a model curriculum. Acad Emerg Med, 9(11), 1310-1318. https://doi.org/10.1111/j.1553-2712.2002.tb01593.x

Sun CY., Qin J., \& Wang Z. (2005). A Preliminary Study on Application of Physiological Driving High fidelity simulation technique for emergency medicine training in China. Chin J Crit Care Med, 25(9), 682.

Sun JW., Liu CX., \& Shi N. (2010). Effects Simulating Education in Developing Medical Students Resuscitation Skills and Clinical Emergency Rapid Response. China Medical Education Technoloy, 24(4), 391-393.

Sun JZ., Yang M., Chen XQ., You W., \& Sun YL. (2012). Study on Education Mode of Clinical Thinking for Medical Students. Health Vocational Education, 30(6), 11.

Wang B. (2012). Encourage Clinical Practical Education Improvement to the Challenge. China Higher Education, 2, 51.

Yang J., Zhang MY., Liu FN., Huang SM., \& Feng L. (2015). The ultimate goal of clinical skills training. Biotechworld, 7, 249-253.

Yang W. (2013). Analysis and assessment of clinical skills competition (Huabei division) for medical students in medical colleges and universities. China Higher Medical Education, 346. 
Zhao SY., Dai YL., \& Fan Z. (2011). Analysis on the Effect of Medical Interns ' in Humanistic Care Training. Health Vocational Education, 29(23), 126. 